\title{
LA TRADUCCIÓN DEL HUMOR INTERTEXTUAL AUDIOVISUAL. QUE LA FUERZA OS ACOMPAÑE
}

\author{
Carla Botella Tejera \\ cbotella@ua.es \\ Universidad de Alicante
}

\section{Resumen}

Este artículo es una aproximación a la traducción de referencias intertextuales cómicas presentes en producciones audiovisuales. En primer lugar, se centra en explorar diferentes teorías sobre el humor, para después describir las principales características de los referentes culturales audiovisuales. A partir de todo lo que acabamos de mencionar, el artículo tratará de mostrar que recurrir al uso de alusiones puede provocar un efecto paródico, por lo que los traductores deberán ser capaces de trasladar esos mismos matices humorísticos para conseguir que la nueva audiencia se encuentre en igualdad de condiciones que la de la producción en su versión original.

\begin{abstract}
"The Translation of Intertextual Audiovisual Humour. May The Force Be With You"

This article is an approach to the translation of humorous intertextual references in audiovisual productions. Firstly, it deals with different theories of humour to then describe the main characteristics of audiovisual cultural references. Based on all the above mentioned, this article will show how allusions can certainly result in parody. Therefore, translators should take into account that humorous nuances should be transferred so that the new audience is on an equal footing with the original one.
\end{abstract}

Palabras clave: Traducción audiovisual. Humor. Intertextualidad. Referentes culturales.

Keywords: Audiovisual Translation. Humour. Intertextuality. Cultural References. 
Manuscript received on June 30, 2016 and accepted for publication on September 10, 2016.

Para enlazar con este artículo / To link to this article:

http://dx.doi.org/10.6035/MonTI.2017.9.3

Para citar este artículo / To cite this article:

Botella Tejera, Carla. (2017) "La traducción del humor intertextual audiovisual. Que la fuerza os acompañe" In: Martínez Sierra, Juan José \& Patrick Zabalbeascoa Terran (eds.) 2017. The Translation of Humour / La traducción del humor. MonTI 9, pp. 77-100. 


\section{Introducción: breve acercamiento al humor}

El humor es, sin duda, un interesante y controvertido campo de estudio. Son muchas páginas las que se han escrito en busca de definiciones que consiguieran aunar todo aquello a lo que alude este término. Incluso hay autores como Attardo (1994: 3) que han sugerido que resulta prácticamente imposible encontrar una definición para un proceso tan sumamente complejo:

Not only has it not been possible to agree on how to divide the category of "humor" (e.g. "humor" vs. "comic" vs. "ridiculous"), but it is even difficult to find a pretheoretical definition of "humor" in the most general sense. As a matter of fact, the claim that humor is undefinable has been advanced several times.

Si nos remontamos mucho más atrás, parece ser que en la antigua Grecia se utilizaba el término humor para designar a cada una de las sustancias líquidas o semilíquidas que contiene el cuerpo humano. Es interesante entender que, desde esta perspectiva, es necesaria la mezcla de esos cuatro elementos para encontrar el equilibrio. Hipócrates (470-377 a. C.) fue uno de los pensadores que impulsó esta doctrina, cuya visión implica que el hombre afronta equilibradamente su realidad vital (Carbelo 2006: 18). De lo expuesto anteriormente se deriva que alguien está de buen humor cuando tiene salud, cuando todo funciona bien en su organismo. Lo contrario sucede si no existe dicha armonía. La risa, por su parte, sería una expresión positiva del sentimiento. Así pues, el humor estudiado desde ese prisma sería un modo de entender la relación entre el ser humano y lo que le rodea, sea cual sea la relación entre ambos. Las teorías expuestas en algunas obras de Freud (1978) y Bergson (1984) fueron de gran influencia en la investigación del humor y en el impacto de la risa.

Siguiendo esta línea de pensamiento, son muchos los que centran su estudio en la risa como consecuencia del humor, como elemento positivo que surge a partir del mismo y que se podría describir, en palabras de Vandaele (1995: 1), como: "a physical laughter, this strange convulsion as an apparently unambiguous outcome and sign of a psychological reality, or smiling, or even an 'inner' feeling which comes close to laughter". Así, ese laughter sería para Attardo (1994: 10-11) el criterio común a la hora de definir un acto 
humorístico, quedando conectado el humor al fenómeno neurofísico de la risa y entendiendo que se considera gracioso aquello que consigue hacerte reír.

El mismo autor nos dice que lo que sí está bien claro es que el humor se basa en el acto perlocutivo, es decir, en la suma del contexto más la interacción entre emisor y receptor. En palabras de Alcaraz (1990: 149-150), el efecto perlocutivo "surge de las circunstancias de la enunciación y, por lo tanto, no nace sólo por la simple emisión de un enunciado, sino en un determinado contexto, y comprende los efectos, deseados o no, a veces imprecisos o poco claros que cualquier enunciado puede producir en unas determinadas circunstancias".

Otra propuesta que nos resulta interesante es la de Nash, que estudió a fondo el humor y que reconocía la importancia del lenguaje como mecanismo de creación del mismo al apuntar que el acto del humor tiene tres referentes principales (1985: 9-10):

a) A 'genus' or derivation, in culture, institutions, attitudes, beliefs, typical practices, characteristics, artefacts, etc.

b) A characteristic design, presentation or verbal packaging, by virtue of which the humorous intention is indicated and recognized.

c) A locus in language, some word or phrase that is indispensable to the joke; the point at which humour is held and discharged.

Respecto a los mecanismos de creación de humor, Vandaele (1995: 255) destaca la incongruencia, que en su opinión es un elemento básico del humor y que siempre ha sido una consideración central -la característica principal del humor- en la tradición teórica; y destaca también la superioridad, que se manifestaría como un aumento de la propia felicidad del individuo. La incongruencia, en su opinión, podría ser lingüística, pragmática, narrativa, intertextual o paródica (a la que considera como un parásito de los otros géneros), social o satírica y natural, y se produce cuando lo que sucede no concuerda con lo pensado, con lo esperado. Es decir, cuando se rompe la idea que teníamos sobre lo que iba a ocurrir y se produce sorpresa por la inconsistencia entre la realidad y el pensamiento. Resulta interesante para este estudio que la incongruencia pueda ser intertextual y que, por lo tanto, el autor considere la intertextualidad como uno de los posibles mecanismos de creación de humor. Las teorías sobre la incongruencia han sido respaldadas por pensadores como Kant o Schopenhauer. De hecho, este último, en su obra El mundo como voluntad y representación (1985 [1819]), habla de la sorpresa, del cambio inesperado e imprevisto como mecanismo posible de producir risa (Carbelo 2006: 20-21).

Una posible vía de producción humorística para crear incongruencia es, precisamente, la ruptura de las máximas conversacionales de Grice. Autores como Attardo (2002) o Nash (1985) señalan que los chistes suponen la ruptura 
de, al menos, una de las máximas y, además, para la producción del efecto humorístico debe darse también una ruptura en lo establecido entre emisor y receptor. Por su parte, Yus (2003: 1313) opina que la incongruencia no puede actuar sola en la producción del humor, sino que debe darse la unión de tres elementos: "1) the actual resolution of incongruous ongoing interpretations; 2) the realization of having been fooled by the communicator; 3 ) a positive interaction of the joke with the addresse's cognitive environment". Es decir, es importante que haya constancia de la incongruencia por parte del emisor y del receptor para que esta sea efectiva y no se pase por alto.

En cuanto a la superioridad, Vandaele (1995: 257) habla de superioridad negativa y superioridad positiva como distintas sensaciones capaces de producir humor. El hecho de sentirse superior a los demás o de estar por encima de los otros o de uno mismo es un factor capaz de arrancar la risa, de ahí el carácter social de la misma. Una vez más, la superioridad no podrá producir humor por sí sola.

Otra de las líneas de investigación sobre el humor nos lleva a teorías sobre la liberación de tensión, que tratan de rellenar algunos espacios que no cubren las teorías de la incongruencia y la superioridad. En este sentido, se distinguen la tensión física y la psicológica, capaces de restablecer el equilibrio mencionado anteriormente (Carbelo 2006: 25-26).

Además de todas las características que hemos ido mencionando, el humor es culturalmente específico, aunque también tratemos de demostrar su universalidad. Por eso, estamos de acuerdo con Martínez Tejerina (2008: 38) cuando apunta que:

La convivencia cultural nos demuestra que todos los pueblos ríen, pero no lo hacen ni por los mismos motivos, ni en las mismas ocasiones, ni con los mismos referentes. Es decir, el humor es un hecho aparentemente contradictorio, en el sentido de que se trata de un fenómeno universal, que al mismo tiempo se encuentra encerrado en fronteras culturales y lingüísticas concretas.

Así pues, el humor se da en "comunidades" (Martínez Sierra 2008: 133) que comparten una serie de conocimientos y convenciones. Como mencionaba Nash (1985: 9-10), una de las características que define al humor es la importancia de la cultura, actitudes, creencias, etc. de una sociedad.

Ahora bien, estamos de acuerdo con Gillies (1997: 352) en que las diferencias entre las culturas no son las únicas que cuentan a la hora de que un texto resulte humorístico. Lógicamente, también cuentan las diferencias individuales que hacen que cada ser humano sea único y distinto a los demás. 
De este modo, si repasamos todas las características que hemos ido describiendo en este punto, y al no encontrar una definición satisfactoria del término, podríamos afirmar respecto al humor que:

1) La cultura de la comunidad es muy importante en lo que nos resulta humorístico. Las actitudes y creencias de una determinada sociedad influyen y dan forma a lo que se entiende por humor.

2) Puede provocar risa. Lo que es gracioso nos hace reír, y lo que nos hace reír es gracioso. Hay una conexión entre el fenómeno mental del humor y una compleja manifestación neurofisiológica: la risa (Attardo 1994: 10).

3) El elemento lingüístico puede ser fuente de creación de humor.

4) Se basa en el efecto perlocutivo; el contexto y la finalidad son básicos en la creación de humor.

5) Se puede producir mediante la ruptura de las máximas conversacionales; es decir, mediante una ruptura entre lo esperado y lo que sucede (incongruencia y superioridad), aunque tiene que haber constancia de dicha ruptura para que sea efectiva.

6) Permite evadirse y liberar tensiones físicas y psicológicas.

Tras la dificultad de elaborar un listado de las características de lo que entenderemos por humor, todavía nos queda describir el proceso mediante el que se transmite y se recibe, hecho que intentaremos aclarar en el punto siguiente.

\section{Transmisión y recepción del humor}

Como sabemos, en todo proceso de comunicación será la relación comunicativa establecida entre emisor y receptor la que dará lugar a la transmisión de la información o, en palabras de Torres (1999: 93),

su tarea [la del emisor] consiste en provocar un estímulo verbal que el oyente ha de utilizar como una base para recuperar el sentido del enunciado y, para ello, debe hacer una evaluación previa de los supuestos contextuales que el oyente necesita seleccionar para la interpretación y de los procesos inferenciales en pos de la búsqueda de la pertinencia óptima.

Sobre esto, Yus (2010: 1) comenta que "on the speaker's side, there is certain control over what inferential paths the interlocultor is expected to take"; es decir, que el emisor puede prever cierta información, cierto bagaje en la memoria del receptor para poder procesar el humor, el chiste, hasta extraer la comicidad del mismo. Por lo tanto, para acercarnos al humor debemos también acercarnos a la pragmática. Así, tal y como afirma Martínez Sierra (2004: 226) entre el emisor y el receptor debe existir cierto grado de conocimiento previo 
compartido para que los chistes puedan tener éxito. Sobre esto, Sperber \& Wilson (1986: 58) insisten en la importancia de que el receptor sea capaz de inferir y apreciar la intención comunicativa del emisor, por lo que para ambos autores el propio hecho de decodificar esa información es lo que dota de input al proceso de comprensión. En este proceso, Yus (2003: 1304-1307) establece diferentes fases por las que el receptor debe pasar para poder extraer la forma lógica (el oyente o receptor se dedica a decodificar y ordenar los constituyentes gramaticales): resolver la ambigüedad a partir del contexto; determinar el significado real de lo que recibe a pesar de la polisemia y otras características similares y enriquecer la carga semántica y encontrar las implicaciones derivadas, basándose nuevamente en el principio de relevancia de Sperber \& Wilson (1986: 383).

Por otro lado, y a pesar de la importancia de la relación comunicativa entre ambos, nos parece importante insistir en que el humor depende en gran medida del contexto comunicativo y que el emisor solo podrá plantear hipótesis y prever la reacción del receptor. Sperber \& Wilson (1986: 58) nos dicen que "[Communicators] can have some controllable effect on their audience's cognitive environment, but the effects of these modifications are only partly predictable by the speaker". Lo ideal es que, en principio, el emisor tenga en cuenta, tal y como propone Rubio Santana (1996: 225), que el receptor es el adecuado para conseguir el efecto deseado por el chiste, que las circunstancias que rodean al receptor en el momento del intercambio son favorables y que el receptor tiene el suficiente conocimiento cultural para poder inferir los matices que llevan a provocar el efecto humorístico.

De este modo, el receptor no puede actuar de modo pasivo, sino que es él quien crea la significación en el proceso comunicativo, no solo para descifrar la intertextualidad, sino también para extraer la comicidad.

Apoyándonos en la clasificación de Chaume (2004: 165) de los problemas específicos de los textos audiovisuales, en nuestro estudio encontraremos, principalmente, dificultades en el código lingüístico, complementado semióticamente por el código iconográfico; es decir, la imagen podrá complicar la traducción, o facilitarla. Veremos más adelante, cuando nos adentremos en el campo de la traducción del humor que, tal y como afirma Zabalbeascoa (2005: 185), el humor y los estudios sobre traducción se superponen y que, por lo tanto, siempre que un traductor se aproxime en su labor a uno de los dos campos, aquello que descubra en uno le llevará hacia el otro y le hará interesarse por el mismo. 


\section{El intertexto como elemento paródico. La intertextualidad audiovisual en el humor: los referentes culturales}

Antes de seguir avanzando y de acercarnos a la traducción del humor y, más concretamente, de describir el proceso en la modalidad audiovisual, consideramos importante explorar el concepto de cultura y su innegable e inseparable relación con el humor en forma de referentes culturales que, si bien suelen resultar bastante cómicos, al mismo tiempo pueden complicar enormemente la labor del traductor.

De las posibles acepciones que nos ofrece el diccionario de la Real Academia, el concepto de cultura al que aquí nos referimos es el "conjunto de modos de vida y costumbres, conocimientos y grado de desarrollo artístico, científico, industrial, en una época, grupo social, etc." Autores como Sales (2003) y Martínez Sierra (2008) matizan esta definición, y entienden la cultura como algo dinámico, que está en proceso de cambio constante. Se mantienen algunas tradiciones, otras se pierden, y se adquieren nuevas costumbres. Es lo que en los estudios de adquisición de lenguas se conoce como "cultura con mayúsculas" frente al conjunto de conocimientos de un individuo, que sería la "cultura con minúsculas".

El humor es parte de la cultura. Es culturalmente específico. Se transmite y adquiere al vivir en una determinada sociedad. Por eso, tenemos lo que denominamos referentes culturales que, basándonos en la definición de Agost (1999: 99), son los que permiten a las sociedades diferenciarse entre sí, proporcionando una idiosincrasia propia a cada cultura. Para la autora, los pueblos, ciudades, lugares de algún país, así como la literatura, canciones, conceptos estéticos, personajes famosos, gastronomía, moneda, etc. que son característicos de una sociedad podrían considerarse elementos culturales. Son muchos los autores -cf. Delabastita (1990), Agost (1999) o Martínez Sierra (2008) - que destacan la importancia del contexto cultural para la comprensión de estos elementos.

La cultura (con mayúsculas) es propia y característica de un grupo social, de un conjunto de individuos; es etnocéntrica. Eso sí, debemos ser conscientes de que, en la actualidad, el fenómeno de la globalización también afecta a la cultura y, aunque la distancia entre determinadas culturas sigue siendo estratosférica, la cultura norteamericana, por ejemplo, se extiende cada vez más entre el resto de continentes a través de los medios de comunicación, productos audiovisuales (series, películas, programas...), etc. A este respecto, en su repaso del contacto entre las culturas y el papel de los medios de comunicación de masas, Martínez Sierra (2008: 90) habla de que es posible que nos encaminemos hacia una "uniformidad cultural". Compartimos el temor con el autor 
y también nos preocupa que la cultura norteamericana ${ }^{1}$ llegue a extenderse todavía más, hasta el punto de que asumamos algunas de sus costumbres o tradiciones como propias. Por otra parte, la ventaja sería que este fenómeno también facilita la comprensión de productos norteamericanos y puede hacer más fácil la traducción de algunos elementos que ya no resultan tan ajenos ni desconocidos para el público de nuestro país.

Es importante vincular la cultura y la intertextualidad para poder después entender el intertexto como parodia. Marco (1998: 185-190) considera dentro del contexto de cultura a los elementos culturales, las maneras en las que se agrupan los textos, y a la intertextualidad. Esta última y los elementos culturales forman, por lo tanto, parte de la cultura. La intertextualidad es, sin duda, una fuente de humor, como señala Nash (1985: 80): "Allusion can be an important, indeed cardinal, device in the structure of comic texts".

Para Iampolski (1996: 10), la teoría de la intertextualidad bebe de tres fuentes fundamentales: las ideas teóricas de Tyniánov, las de Bakhtin y la teoría de los anagramas de Saussure. Lo interesante para nuestra investigación es que, tanto Tyniánov como Bakhtin se enfrentaron al problema del intertexto a través del estudio de la parodia. En palabras de Iampolski (1996: 10), ambos veían en la parodia:

[...] un principio fundamental de la renovación de los sistemas artísticos, basado en la transformación de textos precedentes. La parodia se representa como un texto de dos planos, a través de cual "se transparenta" según su expresión, el texto predecesor.

Otro argumento de esta opinión que nos parece interesante, y que también comparten otros autores es, de hecho, que Iampolski entiende la parodia como un principio capaz de renovar los sistemas artísticos, ya que mediante ella se pueden transformar los textos anteriores dando lugar a nuevos textos, en los que se puede observar el texto al que hacen referencia.

A este respecto, hablando de los nuevos textos que se generan, también resulta de interés apuntar que esos nuevos textos cómicos no solo dependen del original al que hacen referencia, sino que es importante cómo se contextualicen para resultar cómicos en sí mismos y no depender tanto humorísticamente del texto en el que se apoyan.

En este punto, volvemos a Vandaele (1995: 255) para profundizar en lo que el autor entiende por incongruencia intertextual o paródica. En primer lugar, como comentábamos brevemente, la considera un parásito del resto de

1. El autor recoge el término "Macdonaldization", empleado por Chiaro (2003: 14) y que resulta especialmente ilustrativo para describir el fenómeno de la uniformidad cultural. 
las incongruencias por depender de ellas y por imitar un determinado estilo mediante la combinación de algunos elementos alusivos y transgresores. La unión de estos últimos, de naturaleza tanto verbal como visual, activa la memoria para evocar y alterar, por medio de la incongruencia, las construcciones mentales que el receptor tiene almacenadas en relación con el género o estilo parodiado.

Lorenzo (2005: 136), por su parte, se ha aproximado a las funciones intertextuales que dependen, en todo caso, de un conocimiento compartido o de algún tipo de complicidad implícita o explícita entre emisor y receptor, y de entre las que destacan la función humorística, la de construcción del discurso y la apelativa. La autora insiste en que la humorística es una de las más habituales y que, aunque aparece básicamente en géneros de entretenimiento y diatribas políticas, también es posible encontrarla en gran variedad de géneros y tipologías textuales. Para nosotros, como hemos venido comentando, en aquellas producciones audiovisuales donde destaque la función humorística, el traductor deberá luchar por mantenerla para dejar en igualdad de condiciones a los nuevos receptores. Cierto es también, como comenta la autora, que el terreno político es fuente de numerosas alusiones paródicas.

Ya hemos comentado que Nash (1985: 45) considera las referencias paródicas como una de las posibles vías de creación de chistes, y el autor explica que, en ocasiones, esas referencias se verán afectadas por los juegos de palabras, así como por sustituciones, por lo que nuevamente hablamos del elemento lingüístico como fuente de creación humorística. La intertextualidad puede ser, por lo tanto, un elemento paródico, tal y como opina Nash (1985: 80) "[...] wherever allusions occur some excursion into parody is possible; the parodic line often begins with the allusive point". El hecho de referenciar, ya sea una obra, pasaje, personaje, etc. puede venir acompañado de una intención cómica que no pretende sino establecer una relación de complicidad con los receptores que, una vez detecten la intertextualidad, descubrirán el elemento humorístico derivado del uso de la misma. Ahora bien, el mismo autor advierte que, en ocasiones, nos encontraremos ante lo que él denomina "pseudoparody" en aquellos casos en los que "the sense of recollection is vaguer, and the writer appears to be imitating, in general, the kind of rhetoric appropriate to a convention or genre" (1985: 100). En cualquier caso, y teniendo siempre presente que a veces el humor intertextual vendrá disfrazado de pseudoparodia, no podemos negar que la parodia bebe de la imitación y que, por tanto, estará altamente relacionada con el uso de la intertextualidad.

Además, otro elemento capaz de generar humor, pero a la vez de complicar la tarea del traductor, es la propia deformación de la intertextualidad. 
Un ejemplo de deformación podría ser: Let my pidgeons go, parodiando la frase Let my people go, en este caso mediante el uso de la paronimia, en el capítulo 12 de la primera temporada de la serie de televisión creada por Seth MacFarlane Family Guy. Se trata, por cierto, de una referencia a la película The Ten Commandments (Cecil B. DeMille 1956) (Botella 2010: 109). En cualquier caso, y además de suponer una dificultad añadida, como opina Agost (1999: 103-104) el traductor tendrá que valorar los conocimientos del receptor para que esa deformación cómica sea igualmente graciosa en la nueva lengua; en palabras de la autora, "en una traducción para el doblaje, el traductor siempre ha de recordar que su destinatario es el gran público y qué tipo de texto está traduciendo".

De todas maneras, nos parece interesante mencionar la diferencia entre la referencia utilizada a modo de homenaje (en ocasiones mediante la recreación de una escena o en el mismo escenario que apareciera en otro largometraje, por ejemplo, aunque a veces sea puramente lingüística), y aquella que simplemente pretende arrancar la carcajada del receptor aunque, en ocasiones, la línea que las divide es ciertamente fina y se puede pretender crear ambos efectos. En muchas series, como la anteriormente mencionada Family Guy, las alusiones, por mucho que pretendan homenajear a una película, una serie o un actor/ actriz, siempre tienen como objetivo hacer reír al espectador, dada la naturaleza cómica, subversiva e irreverente de la misma. También es importante tener en cuenta que, en traducción audiovisual, muchas de estas referencias solo contarán con el sema visual, que podrá ser suficiente para percibir el intertexto. Así, habrá momentos en los que la imagen sea portadora de intertextualidad por sí misma, sin hacer uso del código lingüístico. Ahora bien, si la imagen puede ser fuente de intertextualidad, en ocasiones con intención humorística, también podrán serlo las voces o la inflexión verbal (imitaciones, maneras características de hablar, etc.) (Martínez Sierra 2004: 170). Sin duda, estas marcas o señales podrán servir de ayuda para descubrir la intertextualidad detrás de las frases y palabras de los personajes. Profundizaremos en este tema cuando hablemos de los mecanismos que favorecen la detección de la intertextualidad audiovisual.

De lo visto en los dos puntos anteriores podemos resumir que la intertextualidad forma parte de la cultura con mayúsculas y puede ser fuente de humor. Obviamente, y como en todo proceso comunicativo, se presupondrá un conocimiento compartido entre emisor y receptor para poder recibir los elementos humorísticos que se pretendían transmitir. Las alusiones o referencias son consideradas por autores como Nash (1985) un elemento básico en la creación de humor. También hemos observado que el humor intertextual 
puede ser en realidad una pseudoparodia. Por último, hemos visto que será importante prestar atención a posibles deformaciones de intertextos y a elementos no solo visuales, sino también auditivos.

Al estudiar las características del intertexto paródico, hemos convenido afirmar que el efecto humorístico del nuevo texto será mucho más que un simple reflejo de lo que transmitía el texto original. Para profundizar en este tema, debemos ahora acercarnos a los elementos y restricciones que rodean a la traducción del intertexto audiovisual humorístico o paródico, así como a los mecanismos que nos permiten detectarlo.

\section{La traducción del humor intertextual audiovisual}

"There is no such a thing as "untranslability"

(Whitman-Linsen 2001: 145).

Se ha escrito mucho sobre la traducibilidad o intraducibilidad del humor. Hemos empezado este apartado con una sentencia de Whitman-Linsen, para ser optimistas en el enfoque, aunque nos parece una opinión discutible. Bastantes autores, sin embargo, son algo más pesimistas y hablan de una pérdida en la carga humorística de la traducción. Otros, con visión mucho más optimista, creen que es posible. ${ }^{2}$ No nos interesa entrar en este debate, puesto que asumimos la traducibilidad del humor dentro de ciertos límites. El enfoque descriptivista y funcionalista de nuestro estudio implica que entendamos que la traducción del humor funcione si la nueva sociedad receptora lo acepta como tal.

Está claro que, en lo que a la traducción del humor se refiere, si todo traductor debe ser bicultural a la vez que bilingüe, quien pretenda traducir pasajes humorísticos también "debe realizar un gran esfuerzo imaginativo y poseer una creatividad especial así como una competencia lingüística muy extensa" (Agost 1999: 108). El hecho de asumir que es posible traducir el humor no implica en ningún momento que se trate de una labor fácil. Como iremos viendo, son muchos los factores a tener en cuenta en la traducción del humor y, en el caso que nos ocupa, en la modalidad audiovisual del doblaje.

El conocimiento y la experiencia previa son cruciales a la hora de la comunicación y de la transmisión del humor, como ya hemos ido observando. Asimismo, hemos hablado del componente cultural del humor cuando

2. Para profundizar en este tema de un modo resumido, recomendamos el punto traducibilidad frente a intraducibilidad del humor (audiovisual) que realiza Martínez Sierra (2008: 125-127). 
clasificábamos a la intertextualidad dentro de la cultura propia de una sociedad. Yule (1996) habla de schemas como una especie de patrones familiares de conocimiento previo. Zabalbeascoa (1993) de memes compartidos. Por su parte, Martínez Sierra (2008) lo denomina bagaje cultural compartido. Es innegable la relación del humor con la cultura propia de cada sociedad (en el caso de nuestro estudio primará la norteamericana, y en este caso las referencias a producciones audiovisuales de la misma, ya que es la mayor fuente de trasvases culturales en la actualidad), y en el traslado hacia el nuevo polisistema no será nada sencillo salvar estos obstáculos. Obviamente, el conocimiento y la experiencia de la audiencia origen y de la audiencia meta no serán necesariamente compartidos, y eso supondrá un reto para la traducción. En su aproximación pragmática, Agost (1999: 108) destaca también la importancia de la intencionalidad del texto audiovisual; es decir, del humor, la ironía, la ambigüedad... Nuevamente nos acercamos al proceso comunicativo y debemos ser conscientes de la importancia de la intención del emisor para cumplir las funciones que se transmitían en el texto original.

Repasada la importancia de los elementos culturales en la producción del humor, y entendiendo que la intertextualidad suele tener una gran carga cultural, en el trasvase de estos elementos de una lengua a otra las opciones en traducción pueden ser conservarlos o sustituirlos. Cuando se trata de un texto escrito, para conservarlos es posible recurrir a repeticiones, adaptaciones ortográficas o terminológicas, a una traducción lingüística o al uso de glosas extratextuales o intratextuales. Si la opción elegida es la de la sustitución, se puede optar por la adaptación ideológica, diferentes tipos de neutralización, naturalización de los elementos culturales, omisión de los mismos o creación autónoma. No existe una norma universal y única sobre la traducción de los elementos culturales, aunque sí que influyen diversos factores macrotextuales y microtextuales que el traductor deberá tener en cuenta. Newmark (1981: 83) comenta, por su parte, que "normally a translator can treat cultural terms more freely than institutional terms", y añade que "since little can be explained to the spectator, cultural terms are more likely to be translated or given a cultural equivalent in a play than in fiction". Esta última afirmación podría aplicarse a la televisión y al cine, y por ello nos resulta interesante. El autor proclama después que la repetición y una discreta explicación es el método que más eficaz resulta en literatura, sobre todo porque lo considera una forma de respeto a las culturas extranjeras. En nuestra opinión, la metodología de traducción de referentes culturales ha evolucionado y en la actualidad la repetición no nos parece la única posibilidad a tener en cuenta. Lo que sí es cierto es que el lector o espectador es lo más importante (además de mantener la finalidad 
comunicativa del texto), y por eso coincidimos con Bassnett (1980: 23) cuando la autora señala, sobre los elementos culturales, que "the emphasis in translation is on the reader or the listener, and the translator must tackle the SL (source language) text in such a way that the TL (target language) version will correspond to the SL version". Otra opinión similar con la que comulgamos es la de Schäffner (1991: 2), ya que comenta que para producir un texto en la segunda lengua (L2) equivalente a un texto en la primera, o lengua origen (L1), el traductor debe tener en cuenta el conocimiento del mundo de los nuevos receptores, y cuando el conocimiento de los receptores de L1 y L2 es diferente, debe asegurarse de compensar esa pérdida en la L2.

Revisadas algunas posibilidades de traducción de los referentes culturales, nos gustaría ahora atender a algunas clasificaciones interesantes ${ }^{3}$ del tipo de humor, como la de Fuentes (2000: 14-17), que distingue entre humor verbal, visual, gráfico y audiovisual. ${ }^{4}$ Resulta interesante, en nuestra opinión, que se considere al humor audiovisual como un género en sí mismo con características propias y, en algunas ocasiones, distintivas. Dentro de él encontraremos elementos verbales y no verbales, pero en nuestro caso serán los primeros los más importantes, aunque en un gran número de ocasiones vendrán acompañados por los no verbales. Como afirma el autor, los elementos verbales tendrán una marca cultural (en algunos casos, por poner un ejemplo, mediante el uso de acentos) que podrá aumentar la carga humorística y, posiblemente, la dificultad de su recepción y traducción. Otra de las clasificaciones de Fuentes, a partir de la situación o localización en la que surge el humor, nos lleva a afirmar que, respecto al humor, a mayor distancia entre las culturas, más complicado resultará trasladarlo, como veíamos en el punto anterior.

Zabalbeascoa (1993: 266), que tantas veces se ha acercado al campo humorístico, agrupa los diferentes tipos de humor según su dirección. Para este autor, el humor puede ser: de entretenimiento, morboso, cáustico, inofensivo y pedagógico.

Vistas algunas de las diferentes clasificaciones del humor y realizado un acercamiento a la traducción de los referentes culturales, debemos ahora profundizar en la transferencia de la intertextualidad con finalidad humorística.

3. Martínez Tejerina recoge, además, otras clasificaciones del humor en su tesis (2008: 34-35): la de Ruch y Rath (1993) witty, funny, exhilarated, amused, original, subtle, activated, puzzled, aggresive, tasteless, embarrasing, indignant, angered, childish, simple, bored y unstimulated; la de Berger (1997) benigno, tragicomedia, ingenio y sátira; y la de Vandaele (2002) comic situation, unintended humour, intended humour y unachieved humour.

4. Otra de sus clasificaciones en la que no nos detenemos es la de distinguir entre humor verbal y humor gestual. 
Es importante entender que se darán varias fases en el proceso: 1) fase de detección intertextual, 2) fase documental y 3) fase de traducción, en la que el traductor deberá decidir cómo afrontar la transferencia de la intertextualidad con finalidad humorística (Botella 2010: 76).

\section{Mecanismos de detección y traducción del intertexto audiovisual humorístico}

Tal y como acabamos de avanzar, la primera fase del proceso consiste en detectar el intertexto humorístico. Para ello, el traductor deberá buscar las "señales intertextuales" que para Hatim \& Mason (1995: 174) son aquellos "elementos del texto que ponen en marcha el proceso de búsqueda intertextual, motivando el acto de elaboración semiótica". En el caso de los textos audiovisuales, las señales llegarán a nosotros a través de dos canales: el visual y el acústico o auditivo. Además, dada la confluencia de códigos, la gran mayoría vendrán a través del código lingüístico, muchas veces acompañado del musical, iconográfico, etc. Por ello, en el caso del campo audiovisual, las señales audiovisuales intertextuales podrán ser las siguientes:

A través del canal visual:

a) Código lingüístico aislado: los títulos de capítulos de series o de películas pueden contener intertextualidad y servir como guía al traductor.

b) Código lingüístico acompañado de una imagen: una frase o cita textual que pronuncia un personaje viene acompañada por otras referencias visuales o por el uso de personajes de un largometraje o serie referenciados. El caso de los dibujos animados resulta especialmente interesante, ya que, con mayor facilidad, pueden aparecer dibujados personajes o escenarios referenciales.

A través del canal acústico o auditivo:

a) Código lingüístico acompañado de alteraciones en la inflexión verbal de los personajes: el hecho de que un personaje altere su voz de algún modo puede resultar un indicio del uso de una referencia. En el caso de series de dibujos y películas de animación, que un actor famoso preste su voz a un personaje puede ser indicador del uso de intertextos.

b) Código lingüístico acompañado de música: el hecho de recurrir a una canción representativa de la banda sonora de un largometraje o producción audiovisual pueden alertar al traductor del posible uso de una referencia. 
Por supuesto, también se darán multitud de casos en los que el traductor no contará con la ayuda de una señal intertextual audiovisual. En tal situación, su experiencia previa y su bagaje cultural y audiovisual serán las herramientas con las que contará en esta primera fase del proceso.

A continuación, tendrá lugar la fase documental, que podrá resultar lenta y tediosa, pero que será necesaria para garantizar que se trata de una referencia y para descubrir la versión referencial de la misma.

Finalmente, tendrá lugar la fase de traducción. Hemos de tener claro que será importantísimo mantener la función cómica, la prioridad comunicativa.

Ya hemos comentado que toda traducción es comunicación, así que deberán respetarse las tan mencionadas máximas. A este respecto, Agost (1999: 104) dice que "los diálogos de los textos audiovisuales forman un todo dinámico en el que los personajes que intervienen cooperan para que haya una comunicación. Los traductores deben mantener los principios cooperativos a pesar de las dificultades y restricciones del texto original". Y es que, a la hora de transferir los elementos humorísticos debemos tener en cuenta el grado de relevancia entre las dos audiencias y, por lo tanto, los dos receptores del humor. Martínez Sierra (2004: 238) explica que pueden darse tres situaciones diferentes entre la audiencia original y la audiencia meta:

1) Que el grado de relevancia obtenido por la audiencia meta sea inferior al de la audiencia origen.

2) Que dicho grado sea similar en ambos casos.

3) Que dicho grado sea superior en el caso de la audiencia meta.

Este último caso (3) será el que menos encontraremos, aunque hemos comentado que algunos autores mencionan que es posible. La aspiración del traductor será intentar lograr que el grado sea similar, aunque resulte complicado y para ello deba emplear los recursos necesarios.

El traductor audiovisual actuará como receptor y emisor de los textos original y meta, para lo cual habrá de percibir y de procesar la información humorística, así como de trasladarla al idioma de la comunidad de destino de acuerdo con las exigencias, las necesidades y las preferencias dominantes en esta última.

Lógicamente, en la modalidad audiovisual, como hemos querido transmitir a lo largo de estas páginas, habrá ocasiones en las que las características propias de la misma puedan dificultar el proceso, en este caso de la traslación del humor de un texto a otro. Para Fuentes (2000: 46-53), algunas de las restricciones en la traducción audiovisual del humor son: 


\section{- La imagen \\ - El ruido \\ - La diacronía \\ - Los títulos \\ - El lenguaje tabú}

La imagen será, lógicamente, el elemento clave y, pese a las restricciones traductológicas a las que suele someter al texto, en el caso de la detección y traducción de la intertextualidad la imagen tendrá una gran importancia. El ruido, como en todo proceso audiovisual, podrá ocasionar problemas. Más concretamente, podremos encontrar lo que Fuentes (2000: 43-56) considera "ruido cultural", siguiendo un poco la línea que acabamos de trazar, y que tiene relación con los elementos culturales presentes o ausentes en una y otra cultura. La diacronía también resultará importante, ya que habrá ocasiones en las que las referencias sean bastante antiguas, y las traducciones referenciales puedan resultar anacrónicas. Los títulos, fuente de intertextualidad, también supondrán dificultades a los traductores y podrán darnos pistas de un posible uso de la misma. A este respecto, añadimos una dificultad propia de la modalidad del doblaje que aporta Zabalbeascoa (1993), como es el uso de la risa enlatada, presente en gran cantidad de series y comedias de situación, lo que quiere decir que el elemento humorístico que debe arrancar la carcajada del espectador tiene que coincidir en ambos idiomas, complicando más si cabe el proceso traductológico. Este fenómeno también se daría en el subtitulado en caso de ser la modalidad elegida para trasladar estos productos a la nueva audiencia en nuestro país; sí que ocurre, por lo tanto, en países subtituladores $y$, en nuestra opinión, la dificultad resulta todavía mayor.

No queremos dejar de comentar que, en los últimos años, son muchos los estudios sobre la traducción del humor audiovisual que se han llevado a cabo. Se puede apreciar cada vez más el enorme interés que este tema suscita y que son muchos los investigadores ${ }^{5}$ que le dedican su tiempo al estudio de las características de la traducción de los elementos humorísticos en la modalidad audiovisual.

En cualquier caso, cabe repetir que, en la traducción del humor, tal y como veíamos en la de los referentes culturales asociados al mismo, es necesario centrar la traducción en los nuevos receptores, atendiendo al conocimiento

5. Un buen resumen de los trabajos publicados sobre el tema en los últimos años es el trabajo recopilatorio de Martínez Sierra (2009) "On the Dubbing of Humor. Tidying up the Room", en el que el autor recoge las principales publicaciones, tesis, artículos electrónicos, etc. de los últimos años. Como su título indica, pone un poco de orden en el tema. 
compartido (llamémoslo schemas, memes o bagaje cultural compartido) y al grado de relevancia entre ambas audiencias. Así, como afirma Vandaele (1995: 25):

[...] it is time and time again up to the translator to predict (a) whether the target group possesses the schemes on which the source text plays and, if so (b) whether these schemes on which the source text plays and, if so (b) whether these schemes have a similar cognitive value, i.e. whether they are as normal for the target group as they are for the source audience.

Así, a la hora de enfrentarse a la traducción de la intertextualidad audiovisual utilizada con finalidad humorística el traductor tendrá varias posibilidades por las que optar. Lorenzo (2005: 142) opina que, en concreto, podrá a) retenerlo cuando sea reconocible por la audiencia meta; b) sustituir el referente por otro conocido en la lengua meta; o c) neutralizarlo cuando puede dificultar la comprensión o crear problemas de coherencia.

Además, Martínez Sierra (2004: 170) nos recuerda que hay que tener en cuenta varios factores en la traducción de estas referencias en el doblaje, entre ellos, los profesionales, el destinatario, la interacción entre las dimensiones pragmática, semiótica y comunicativa y la sincronía. Respecto a esta última característica tan definitoria de la modalidad audiovisual a la que hemos hecho mención, Agost (1998: 226) nos recuerda que, teniendo en cuenta las limitaciones de las restricciones visuales, cuando las citas son famosas, suelen también tener una traducción famosa que el traductor debería intentar mantener.

Así, si el traductor se encontrara con la famosa frase "May the Force be with you", tan repetida en la saga de Star Wars (1977, 1980, 1983, 1999, 2002, 2005 y 2015), y por tanto bastante conocida en su versión en español peninsular, debería, una vez realizado el proceso de detección y documentación oportunos, tratar de mantener su versión referencial si las circunstancias y restricciones audiovisuales lo permiten. El uso de una versión diferente podría decepcionar al espectador o hacer que dicha referencia pasara desapercibida. De esta forma, los nuevos espectadores no estarían en igualdad de condiciones con los de la versión original.

\section{Conclusiones}

En este estudio nos hemos enfrentado a la dificultad de encontrar una definición de lo que es el humor. Nos ha parecido interesante la concepción clásica de que el humor es el equilibrio en el cuerpo y que estar de buen humor es sinónimo de que todo está en orden en nuestro organismo. La risa sería, precisamente, una manifestación de estas sensaciones. 
Tras adentrarnos en algunos conceptos que pueden ayudar a construir una definición de algo tan complejo, hemos llegado a la conclusión de que, puesto que nuestro estudio se centra en la intertextualidad, nos encontraremos con un humor al que acompaña el elemento lingüístico, que ya hemos visto contribuye a producir textos cómicos.

Al estudiar las características que dan lugar a la creación de humor hemos destacado la incongruencia, que supone una ruptura de las máximas conversacionales, y la superioridad positiva y negativa. El humor puede surgir de la ruptura de lo esperado, de lo conocido. También hemos visto que el humor nos permite evadirnos y que puede funcionar para liberar tensiones.

Por otro lado, hemos destacado la risa como elemento positivo que se deriva del acto humorístico y, apoyándonos en el silogismo que proponía Attardo (1994: 10-11), hemos considerado que, lo que nos hace reír es gracioso, y lo que es gracioso nos hace reír. También hemos destacado la importancia del contexto y la finalidad en el acto humorístico, por lo que el efecto que prima suele ser perlocutivo.

Además, hemos comentado que el humor se genera en una determinada sociedad, aunque pueda cruzar las fronteras. Así, las actitudes, las costumbres, las creencias de un determinado grupo pueden cambiar el concepto de lo que se entiende por humor. De todas maneras, hemos insistido también en que no solo cuentan las diferencias culturales, sino que cada individuo es un mundo en sí mismo y puede que lo que entienda como humorístico difiera del resto de los individuos de su misma cultura o sociedad. Para nosotros, las referencias intertextuales pueden formar parte de la cultura de un determinado lugar.

Ahora bien, al acercarnos a la transmisión del humor, hemos observado que el proceso es similar al de la comunicación. Simplificándolo, encontramos la figura de un emisor y de un receptor entre los que un conocimiento compartido puede ayudar notablemente en la recepción del humor. Aunque el emisor puede prever los conocimientos y el bagaje cultural del receptor, en realidad solo puede hacer hipótesis de lo que este podrá descifrar.

Por otra parte, hemos hablado del humor audiovisual, en el que el código lingüístico se ve complementado semióticamente por el código iconográfico (además de por otros códigos como el de sonido, etc.). Obviamente, hemos enmarcado nuestro estudio dentro de este tipo de humor, ya que la intertextualidad se ve complementada por el código iconográfico, el de sonido, el de movilidad, fotográfico, paralingüístico...

También hemos visto algunos conceptos sobre referentes culturales como mecanismos de creación de humor, entendiendo la cultura como las costumbres, los modos de vida, siempre en cambio constante de una sociedad. Por lo 
tanto, la comprensión del contexto cultural será clave para recibir el humor que se halla tras un referente de este tipo. Eso sí, hemos comentado que la globalización está consiguiendo que las culturas se acerquen y que cada vez compartan más elementos, aunque el grado de mediación entre la cultura origen y la meta seguirá siendo determinante para la comprensión de una referencia.

Una vez estudiada la relación de la cultura con el humor, hemos podido apreciar que el intertexto, cultural o no, puede ser un elemento paródico por sí mismo, una serie de frases o palabras que forman un conjunto con intención humorística. Nuevamente, para la recepción de este intertexto paródico es necesaria una complicidad, cierto conocimiento compartido entre el emisor y el receptor. Hay ocasiones, eso sí, en las que hay que tener cuidado con la pseudoparodia, que es solo un reflejo vago, una imitación que no se corresponde con una referencia original. Con intención cómica, también veíamos que podía darse una deformación de la intertextualidad, que en ocasiones puede suponer un problema de traducción.

Precisamente hablando de la traducción del humor, que en este caso hemos dicho que, además, se basaba en el lenguaje, hemos apuntado la dificultad de llevar a cabo esta empresa. El traductor tendrá que asegurarse de salvar los obstáculos, la distancia entre el emisor y el receptor, cuyo conocimiento, cultura y maneras de ver el mundo no serán necesariamente compartidos. Las opciones, tal y como veíamos, son mantener los elementos culturales, sustituirlos por otros u omitirlos, pero siempre se han de tener en cuenta las características de la audiencia meta. Aportando nuestro pequeño granito de arena, hemos determinado que serían al menos tres fases las que debería recorrer el traductor al enfrentarse con un posible intertexto audiovisual: la fase de detección intertextual, la fase documental y la fase de traducción. En la fase de detección, será importante buscar las señales intertextuales audiovisuales que, en los casos en los que aparezcan, llegarán a nosotros a través del canal visual y del canal acústico o auditivo. La confluencia de códigos propia de este medio también podrá favorecer el reconocimiento de la referencia, para continuar con la fase documental en la que se buscará la traducción referencial.

Como conclusión final sobre la traducción del humor audiovisual hemos comentado que, al traducir, es importante mantener los principios cooperativos y tener en cuenta el grado de relevancia entre las dos audiencias, siendo conscientes de que aparecerán elementos que dificultarán la traducción, como el ruido cultural, por ejemplo. En cuanto al proceso comunicativo, el traductor deberá tener en cuenta la finalidad perseguida por el emisor. Si este pretendía producir un efecto humorístico a través del uso de referencias intertextuales, el traductor deberá encontrar los mecanismos que le permitan conseguir el 
mismo efecto en la nueva audiencia. Solo así, ambos receptores estarán en igualdad de condiciones. Además, el traductor deberá tener en cuenta si las referencias tienen una traducción reconocible por la audiencia meta y, atendiendo a las restricciones visuales, al encargo de traducción y al destinatario, entre otros factores, optar por mantenerlas, sustituirlas por otras más conocidas o neutralizarlas en caso de opacidad. La finalidad humorística será, sin duda, la principal meta.

\section{Referencias bibliográficas}

Agost, Rosa. (1998) "Traducció i intertextualitat: el cas del doblatge." En: Messeguer, Luís \& María Luisa Villanueva (eds.) 1998. Intertextualitat i recepció. Castellón: Universitat Jaume I, pp. 219-244.

AGost, Rosa. (1999) Traducción y doblaje: palabras, voces e imágenes. Barcelona: Ariel.

AlCARAZ, Enrique. (1990) Tres paradigmas de la investigación lingüística. Alcoy: Marfil.

ATTARDO, Salvattore. (1994) Linguistic Theories of Humor. Berlín \& Nueva York: Mouton de Gruyter.

AtTARDO, Salvattore. (2002) "Translation and Humour: An Approach Based on the General Theory of Verbal Humour (GTVH)." En: Vandaele, Jeroen (ed.) 2002. The Translator 8-2 (Translating Humour, Special Issue), pp. 173-194.

BASSNETT, Susan. (1980) Translation Studies. Londres: Methuen.

Berger, Peter L. (1997) Reedeming Laughter. The Comic Dimension of Human Experience. Berlín \& Nueva York: Walter de Gruyter.

BERGSON, Henri. (1984) La risa. Madrid: Sarpe.

Botella, Carla. (2010) El intertexto audiovisual y su traducción. Referencias cinematográficas paródicas en Family Guy. Alicante: Universidad de Alicante. Tesis doctoral inédita.

CARBElo, Begoña (2006) Estudio del sentido del humor. Alcalá: Universidad de Alcalá. Tesis doctoral inédita.

Chaume, Frederic. (2004) Cine y traducción. Madrid: Cátedra.

CHIARO, Delia. (2003) "The Implications of Quality of Translated Verbally Expressed Humour and the Success of Big Screen Comedy." Antares VI, pp. 14-20.

Delabastita, Dirk. (1990) "Translation and the Mass-Media." En: Bassnet, Susan \& André Lefevere (eds.) 1990. Translation, History and Culture. Londres \& Nueva York: Pinter, pp. 97-109.

FREUD, Sigmund. (1978) El yo y el ello y otros escritos de metapsicología. Madrid: Alianza Editorial.

FUENTES, Adrián. (2000) La recepción del humor audiovisual traducido: estudio comparativo de fragmentos de las versiones doblada y subtitulada al español de la 
película "Duck Soup”, de los hermanos Marx. Granada: Universidad de Granada. Tesis doctoral inédita.

Hatim, Basil \& Ian Mason. (1985) Teoría de la traducción: una aproximación al discurso. Barcelona: Ariel.

Gillies, Eva. (1997) “¿El humor es traducible?” Alba de América: Revista Literaria, pp. 352-359.

IAMPOLSKI, Mijaíl. (1996) La teoría de la intertextualidad y el cine. Valencia: Episteme, S.L.

LORENZO, Lourdes. (2005) "Funcións básicas das referencias intertextuais e o seu tratamento na traducción audiovisual." Quaderns. Revista de traducció 12, pp.113-150.

MARCO, Josep. (1998) "Intertextualitat i Traducció: les línies bàsiques d'una relació inevitable.” En: Messeguer, Lluís \& Mª Luisa Villanueva (eds.) 1998. Intertextualitat i recepció. Castellón: Universitat Jaume I, pp. 185- 190.

MARTínez TejerinA, Anjana. (2008) La traducción para el doblaje del humor basado en la polisemia: Los hermanos Marx cruzan el charco. Alicante: Universidad de Alicante. Tesis doctoral inédita.

MARTínEZ SiERRA, Juan José. (2004) Estudio descriptivo y discursivo del humor en textos audiovisuales. El caso de los Simpsons. Castellón: Universidad Jaume I. Tesis doctoral inédita.

MARTínez Sierra, Juan José. (2008) Humor y traducción. Los Simpson cruzan la frontera. Castellón: Universitat Jaume I.

MARTínez Sierra, Juan José. (2009) "On the Dubbing of Humor. Tidying Up the Room." Translation Jounal 3. Versión electrónica: <http://accurapid.com/ Journal/49humor.htm>

NASH, Walter. (1985) The Language of Humour. Londres \& Nueva York: Longman.

Newmark, Peter. (1981) Approaches to Translation. Nueva York: State University of New York.

Rubio SantanA, Juan Manuel. (1996) "A Pragmatic Approach to Interaction in Humorous Communication." En: Penas Ibañez, Beatriz (ed.) 1996. The Intertextual Dimension of Discourse. Pragmalinguistic-Cognitive-Hermeneutic Appoaches. Zaragoza: Universidad de Zaragoza, pp. 219-233.

RUCH, Willibald \& Sigrid RATH. (1993) "The nature of humor appreciation: Toward an integration of perception of stimulus properties and affective experience." Humor: International Journal of Humor Research 6, pp. 363-384.

SALES, Dora. (2003) Puentes sobre el mundo: Cultura, traducción y forma literaria en las narrativas de transculturación de José María Arguedas y Vikram Chandra. Castellón: Universidad Jaume I. Tesis doctoral inédita.

SCHÄFFnER, Christina. (1991) "World Knowledge in the Process of Translation." Target 3:1, pp. 1-16. 
SCHOPENHAUER, Arthur. (1985 [1819]) El mundo como voluntad y representación. Barcelona: Orbis.

SPERBER, Dan \& Deidre Wilson. (1986) Relevance: Communication and Cognition. Oxford: Blackwell.

TORRES, Ma Teresa. (1999) Estudio pragmático del humor verbal. Cádiz: Universidad de Cádiz.

VANDAELE, Jeroen. (1995) Describing Translated Humour in Comedy. Lovaina: CETRA.

Whitman-Linsen, Candace. (2001) "Cloning Cultures: The Return of the Movie Mutants." En: Chaume, Frederic \& Rosa Agost (eds) La traduccion en los medios audiovisuales. Castellón. Universitat Jaume I, pp. 143-157.

YULE, George. (1996) Pragmatics. Oxford: Oxford University Press.

YUS, Francisco. (2003) "Humor and the Search for Relevance." Journal of Pragmatics 35, pp. 1295-1331.

YUS, Francisco. (2010) "Relevance, Humour and Translation." $5^{\text {th }}$ Conference Interpreting for Relevance; Discourse and Translation. Kazimierz Dolny (Polonia). Ponencia inédita.

ZabalbeasCOA, Patrick. (1993) Developing Translation Studies to Better Account for Audiovisual Texts and Other New Forms of Text Productions. Lleida: Universidad de Lleida. Tesis doctoral inédita.

ZabalbeasCOA, Patrick. (2005) "Humour and Translation. An Interdiscipline." Humor 18:2, pp. 185-207.

\section{BIONOTE / NOTA BIOGRÁFICA}

Carla Botella Tejera es doctora en Traducción e Interpretación por la Universidad de Alicante. También tiene un máster sobre nuevas tecnologías aplicadas a la Educación. Comenzó a trabajar en CIEE (Consejo de intercambio educativo con el extranjero) en 2005 y ha sido la directora académica de los programas Language in Context y Language and Culture en su centro de Alicante hasta mediados de septiembre de 2016. Carla también es profesora Ayudante Doctora del Departamento de Traducción e Interpretación de la Universidad de Alicante y ha trabajado en otras universidades españolas y europeas.

CARLa Botella Tejera holds a Ph.D. in Translation and Interpreting from the Universidad de Alicante. She also holds an MA. in New Technologies Applied to Education. She joined CIEE (Council on International Education Exchange) in 2005. She has been the academic director for both the Language in Context and Language and Culture programs in Alicante until September 2016. Carla 
is also an Assistant Professor at the Translation and Interpreting Department of the Universidad de Alicante and has worked in other Spanish and European universities. 